\title{
THE STATE OF LOGISTICS: \\ RESEARCH PRIORITIES FOR SUSTAINED IMPROVEMENT
}

\author{
ESBETH VAN DYK \\ HANS ITTMANN \\ MARIO MARAIS \\ ISABEL MEYER \\ EMMA MASPERO \\ hittmann@csir.co.za \\ Logistics and Quantitative Modelling \\ CSIR Built Environment
}

\begin{abstract}
The importance of logistics and supply chain management for the South African economy was re-emphasised by the findings of the CSIR's third annual State of Logistics Survey. To meet current and future demands, the research agenda for logistics needs to be wider than the traditional (mainstream) focus. System inefficiencies as well as specific non-traditional areas need to be explored, e.g. the integration of rural and small businesses, government service delivery, sector cooperation, and emergency logistics. This article provides a brief overview of the current state of logistics in the country and the government's response in terms of the National Freight Logistics Strategy. Research needs, research priorities and the role of research organisations are discussed.
\end{abstract}

\section{INTRODUCTION}

The importance of logistics and supply chain management for the South African economy was re-emphasised by findings of the third annual State of Logistics Survey (CSIR, 2006) conducted by the Council for Scientific and Industrial Research (CSIR). Total logistics costs remained at $14.5 \%$ of the Gross Domestic Product (GDP) in 2006, which is high compared to those of South Africa's trading partners such as the USA, where the logistics costs were 9.9\% of the GDP for 2006. Transport costs are rising globally and, as a transport-intensive economy, the effect thereof is magnified in South Africa.

South Africa is responding to inefficiencies in its logistics system with, among others, the 2005 publication of the National Freight Logistics Strategy (NFLS). This strategy is in the process of being implemented, but requires extensive research support to enable its execution. In order to improve the national logistics system, it is crucial that a knowledge base be developed that fuels national debate on the prime causes of system inefficiencies and the proposed solutions. 
The demands of a developing economy require the research agenda to be wider than the traditional focus on logistics and supply chain management, which usually includes topics such as facility location, inventory, warehousing, transport modes, intermodal transport, distribution, benchmarking, information systems and technology, collaboration and reverse logistics for high-volume global supply chains. In addition to a macro-view on system inefficiencies and topical issues like sustainability and green logistics, specific areas such as the integration of rural and small businesses, government service delivery, sector cooperation and emergency logistics, including humanitarian logistics, need to be explored. Also, research organisations need to create networks with appropriate research partners through whom relevant research can be adopted for local application.

This article provides a brief overview of the current state of logistics in South Africa and the government's response in terms of the NFLS. It then discusses research priorities, research needs and the role of research organisations.

A list of acronyms is given in Table 1.

Table 1: Acronyms

\begin{tabular}{|l|l|}
\hline ASGISA & Accelerated and Shared-Growth Initiative for South Africa \\
\hline CSIR & Council for Scientific and Industrial Research \\
\hline CTL & Centre for Transportation and Logistics \\
\hline DTI & Department of Trade and Industry \\
\hline GDP & Gross Domestic Product \\
\hline GIS & Geographic Information System \\
\hline ICT & Information and Communication Technologies \\
\hline IDTTL & Inter-Departmental Task Team on Logistics \\
\hline NDoT & National Department of Transport \\
\hline NFLS & National Freight Logistics Strategy \\
\hline RFID & Radio Frequency Identification \\
\hline SADC & Southern African Development Community \\
\hline SAJTSCM & South African Journal of Transportation and Supply Chain Management \\
\hline SCM & Supply Chain Management \\
\hline TETA & Transport Education Training Authority \\
\hline UNJLC & United Nations Joint Logistics Centre \\
\hline
\end{tabular}

\section{STATUS OF THE NATIONAL LOGISTICS SYSTEM}

The current status of the national logistics system is characterised by a number of wellpublicised key factors, including the deteriorating road and rail infrastructure, ports inefficiencies, and the cost-ineffective road/rail split of freight. 
The State of Logistics Survey takes a holistic, multi-perspective view on the logistics system, and identifies the following as key characteristics (CSIR, 2005):

- The total cost of logistics is at $14.5 \%$ of GDP. Transportation cost is the biggest cost driver, and has risen by more than $\mathrm{R} 12$ billion in the past year.

- Growth in freight volume is predominantly captured by road.

- Lead industries with respect to supply chain innovation collaborate across industry boundaries to improve the utilisation of the constrained national infrastructure.

- In cost-sensitive industries, firm-level innovation dominates at the expense of channellevel innovation.

- Key logistics challenges inhibit government service provision.

- Targeted investment is required to allow small businesses access to the national logistics infrastructure.

These issues emanate from a number of driving factors. The NFLS highlights two primary aspects, namely prolonged underinvestment in rail infrastructure and a fragmented regulatory environment that is not conducive to the optimal performance of the system.

\section{The problem}

The NFLS was developed by the Inter-Departmental Task Team on Logistics (IDTTL), under direction of the National Department of Transport (NDoT) as a response to the inability of the freight system to fulfil the demands placed on it by economic development and the portfolio of national developmental strategies. The concise summary of the problem statement that the NFLS responds to is:

The freight system in South Africa is fraught with inefficiencies at system and firm levels. There are infrastructure shortfalls and mismatches; the institutional structure of the freight system is inappropriate, and there is a lack of integrated planning. Information gaps and asymmetries abound; the skills base is deficient, and the regulatory frameworks are incapable of resolving problems in the industry.

(National Department of Transport, 2005)

\section{Response to the problem}

The NFLS has developed a vision for freight transport that responds to aspects of the problem statement by realigning the institutional and regulatory frameworks. The purpose is two-fold: to respond to existing problems, and to provide a means for the transformation of the system in order to support the future needs of both the state's developmental strategy and role-players such as cargo owners and logistics service providers.

The vision has a major impact on infrastructure ownership and proposes three categories, namely (National Department of Transport, 2005): 
- state infrastructure utilities that have a strategic and economic developmental mandate

- state-owned enterprises that are commercialised public infrastructure owners with socioeconomic obligations rather than a pure profit agenda

- private sector infrastructure owners.

\section{Implementation of the NFLS}

Two elements are emphasised in the implementation of the NFLS: integrating the first and second economies by developing rural freight transport systems from an integrated freight system perspective, and following an approach to corridor development that prioritises critical corridors.

The all-important integrated planning component of the strategy will be executed by a technical task team, led by the NDoT, that will design and implement a "freight logistics system master plan" for the entire country. The purpose of this plan is to address the lack of integrated planning within the public sphere of the freight logistics system and between the private and public sectors. The plan is to filter the local-level planning up into the provincial growth and development strategies which will, in turn, inform the master plan.

\section{Research requirements of the NFLS}

The research support required for the freight logistics system master plan includes:

- methodologies for accurate freight logistics demand forecasts over five, ten and fifteenyear periods in order to enable effective planning and infrastructure network strategy development, together with a wide range of modelling support for the freight demand forecasts

- a comparison between the forecasts and the planned freight logistics system master plan in order to do an infrastructure gap analysis between market demand and capacity delivery plans in the public and private spheres

- detailed, credible, freight traffic information - this requires the development of an advanced freight database which can be used to provide input into sophisticated infrastructure and other planning systems. To address this need, the NDoT recently launched its new national freight databank (wwwk), which contains data on the volumes of freight on South Africa's road and rail networks, linked to a geographic information system (GIS) platform

- a platform for freight logistics (supported by the freight database) that will have a multitude of functions, including: provision of information for government policy development and decision-making, provision of access to information to all role-players, and provision of a non-proprietary transactional platform to enable supply chain collaboration and performance measurement of key corridors. The Department of Agriculture has commissioned the development of such a platform for agricultural freight 
- integration of the existing Department of Trade and Industry (DTI) corridor performance measurement platform into this platform

- regional planning integration at Southern African Development Community (SADC) level.

The overall implementation of the vision of the NFLS also requires that a spectrum of supporting research be undertaken, aimed at:

- developing a better understanding of rural logistics requirements

- forming a national logistics centre, as an extension of the IDTTL, that can coordinate skills development and research by the Transport Education Training Authority (TETA), unions, academia, and other role-players

- investigating the corridor aspects of the NFLS that require demand analysis, forecasting and the development of a corridor infrastructure and operations investment model. Development of a corridor optimisation strategy is also envisaged.

\section{Status of local research}

The status of logistics and supply chain management (SCM) research in South Africa is not easy to determine. This is due to the limited number of publications on the topic as illustrated by, for example, the fact that the local South African Journal of Transportation and Supply Chain Management (SAJTSCM), launched in 2007, struggled to get sufficient papers for its first issue.

Research is typically conducted at universities and research organisations. In this respect, departments that focus on logistics and SCM are located at the universities of Stellenbosch, Pretoria, Johannesburg and the Witwatersrand, Tshwane University of Technology, and Nelson Mandela Metropolitan University in Port Elizabeth.

The CSIR, as a national research organisation, only recognised the importance of logistics and SCM a few years ago. It recently initiated the State of Logistics surveys and three such surveys have been published (CSIR, 2004; CSIR, 2005; CSIR, 2006). In addition, the CSIR has published a number of papers on work in the fruit industry in the journal of the Operations Research Society of South Africa (Bekker, Mostert \& Van Dyk, 2005; Ortmann, Van Vuuren \& Van Dyk, 2006; Van Dyk \& Maspero, 2004).

In addition to research done at the CSIR, the private sector also commissions research but this is typically aimed at optimising the entire supply chain or elements thereof. Logistics and SCM research is presented regularly at local conferences. In this regard the annual SAPICS conference is possibly the most important one (wwwt). 
Lastly, a few South African-authored textbooks covering logistics and SCM have been published. In the authors' opinion these are comparable to international textbooks (Vogt, Pienaar \& De Wit, 2002; Hugo, Badenhorst-Weiss \& Van Biljon, 2004).

Funding for local research is very limited, and neither the government nor industry is a large contributor to logistics research. Indications are that government departments are more favourably inclined towards providing research funding, especially since there has been a realisation that major problems abound in the national freight logistics infrastructure. In addition, the government's accelerated and shared-growth initiative (ASGISA) recognises the importance of the removal of six constraints to economic growth. One of these constraints is "the cost, efficiency and capacity of the national logistics system, which was pushing up the price of moving goods and conveying services over distance" (Mpahlwa, 2006). This illustrates how seriously the government views the whole area of logistics and supply chain management for South Africa in the years ahead. To address this specific constraint will require an in-depth and concerted research effort, the funding of which will be critical.

\section{THE FOCUS: RESEARCH THEMES}

Logistics pressures in the South African economy centre around addressing systemic inefficiencies that influence export competitiveness, providing infrastructure and services that support both the first and the second economy, and finding innovative means of developing supply chains that can deal with South Africa's distance from most of its major markets.

Players in the economy range from large organisations with advanced logistics capability and access to sophisticated infrastructure, to small businesses with limited capacity to integrate into sophisticated supply chains. There is also a discrepancy between the geographic spread of economic activity and access to logistics infrastructure and services. Economic development requires the development of strategies to provide equitable access to the logistics system, and supply chains that are accessible to small and large players. In the context of the SADC region, South Africa's relatively strong economic position places demands on its logistics capacity, especially when disaster relief or emergency support is required.

As mentioned before, the research base is small and relatively fragmented. Furthermore, logistics is a relatively new research area, associated with a large diversity of disciplines ranging from business management to transport economics.

A comprehensive approach to logistics research is required to address the above complexities: one that takes account of multiple perspectives on the problem, and enables integrated thinking about solutions. 
Eight research themes needed to form the core elements of such a programme are discussed below.

\section{Theme 1 - Addressing structural inefficiencies}

It is well known that the South African transport infrastructure suffers from serious capacity shortages that lead to congestion, for example, on the road networks in Gauteng and Cape Town, on the Johannesburg-to-Durban corridor and in the container terminals at the ports of Durban and Cape Town (National Department of Transport, 2005). The ability to compete as a nation in a global economic arena is critically dependent on an efficient and effective logistics system. Research to support the development of such a system takes a predominantly macro-view, and develops a body of knowledge pertaining to:

- structural inefficiencies and how to address them

- economic infrastructure and its impact on logistics

- logistics as an enabler of national competitiveness

- implementation challenges of the NFLS.

This theme is on the research agenda in many countries. For example, the Logistics Association of Australia has sponsored a study on the Australian state infrastructure (wwwo) and the Melbourne University has a research centre for Integrated Freight Systems Management (wwwi). The European Union 6th Framework Programme included freight transport corridors and intermodal freight transport systems, technologies and strategies as research domains (wwwa). In The Netherlands, research on integrated national and European logistics networks and on the accessibility of the main ports (seaports and airports), including the integration of various modes inside the ports as well as the connectivity to the hinterland, is funded by Connekt (wwwj, wwwy) while the Holland International Distribution Council also supports research on European logistics networks and multimodal networks (wwws).

\section{Theme 2 - Supply chain collaboration and sector cooperation for competitiveness}

The firm-level focus on logistics efficiency implies that firms are creating their own optimal operations, without necessarily improving their efficiency as channel partners. It is important to develop knowledge that will enable supply chain partners and industry sectors to collaborate for improved international competitiveness; and to influence the development of the national system to address collective logistics requirements.

Internationally, supply chain collaboration is one of the major focus areas of mainstream logistics and SCM journals. A good example of sector cooperation is "Platform Agrologistics", an initiative by the Dutch government and agricultural industry to improve logistics efficiency in the agricultural sector in The Netherlands (wwwc). This has led to a variety of innovative projects (wwwd) and an agro-logistics Community of Practice (Kranendonk \& Kersten, 2005). 


\section{Theme 3 - Firm-level efficiency}

Effective utilisation of the national logistics system requires that individual firms optimise their performance, specifically in the context of the particular national logistics system within which they operate. Companies should benchmark their performance locally and internationally in order to identify areas for improvement.

Logistics benchmarking is another one of the major focus areas of mainstream international logistics and SCM journals, while logistics best practice was one of the research domains of the European Union 6th Framework Programme.

\section{Theme 4 - Supply chain security}

Security concerns in developed economies are placing increasing demands on supply chain security, as does the traceability of goods along a chain. Tools and processes need to be developed that enable cost-effective compliance with security and traceability requirements.

Numerous conferences and pilot projects worldwide have been dedicated to supply chain security and/or traceability in supply chains and especially the use of radio frequency identification (RFID) for this purpose (Abell \& Kay, 2005; Helferich \& Cook, 2002; wwwg; wwwq; wwwy). MIT researchers at the Centre for Transportation and Logistics (CTL) have conducted studies to understand how supply chains are affected by disruptions such as terrorist attacks, natural disasters and other logistical failures (wwwb). Researchers at Stanford recently published a white paper on supply chain security (wwwv), while the LBJ School of Public Policy at the University of Texas at Austin (funded by Congressional Research Services) conducted an international study of the adoption of maritime security measures (wwwx). Private sector firms such as IBM (wwwf) and APL (wwwe) are also conducting research on the subject.

\section{Theme $\mathbf{5}$ - Logistics modelling and technology tools}

Logistics efficiency can only be improved if decisions are based on accurate information. However, in South Africa there is a tendency not to share information at firm and supply chain level for fear of losing competitive advantage. At national level there is a general lack of relevant data. A need exists to develop a suite of models, ranging from a macroeconomic to a supply chain perspective, aimed at assisting decision-making. The use of information and communication technologies (ICT) should also be explored to facilitate collaboration and synchronisation in the supply chain.

Logistics modelling and simulation are major focus areas of mainstream international logistics and SCM journals. A survey of doctoral dissertations in the USA has shown that more than twenty per cent of all the dissertations included some aspect of decision-support 
systems (Stock \& Broadus, 2006). In Canada, information and decision technologies are one of the five research themes of the Inter-university Research Centre of Enterprise Networks, Logistics and Transportation (wwwh).

\section{Theme 6 - Small-business and rural logistics}

While the focus of economic development is on the growth of small enterprises, logistics services and infrastructure are inaccessible and cost-inefficient for such enterprises. Strategies are required to reduce the logistics divide between the first and second economies, both from a rural corridor perspective, and from the perspective of having small and large players participating in the same channel.

Very little research has been published on small-business logistics, but a few relevant international papers were found (Bonfatti \& Monari, 2006; Gélinas \& Bigras, 2004; Hu 2003).

\section{Theme 7 - Emergency logistics}

South Africa's relatively strong role in the region places a demand on its logistics system for the delivery of goods in the event of humanitarian crises, such as the floods in Mozambique, Zambia and Zimbabwe in 2007/8 (wwwn, wwwr). Knowledge should be developed pertaining to the capacity to deliver emergency logistics support, the impact of the national logistics system on normal operations, and strategies for developing flexibility in the system to respond in emergency situations.

The Fritz Institute, Georgia Tech's Center for Humanitarian Logistics (both in the USA) and INSEAD (France) are three of the most prominent research groups in this new field (Van Wassenhove, 2006; wwwl; wwwm; wwwu). Humanitarian logistics practitioners are also contributing to knowledge development through initiatives such as the United Nations Joint Logistics Centre (UNJLC), which is an inter-agency Humanitarian Common Service mandated to provide a platform for logistics information as well as commodity tracking and prioritisation services (wwww).

\section{Theme 8 - Government service delivery}

The ability of government to deliver services is largely dependent on its ability to manage its logistics operations, often in remote areas. Delivery of education, health care, and home affairs products and services are good examples. The logistics focus in government is often still on procurement, while optimisation of the entire supply chain is lacking. Research is needed that will enable improved government service delivery. Links exist between this theme, rural logistics and emergency logistics (Fox, 2005).

The LMI Research Institute in the USA specialises in the "science of government management" of which logistics management is a key focus area (wwwp). 


\section{ROLE OF RESEARCH ORGANISATIONS}

The research focus as outlined in the previous section requires that a number of players integrate their efforts for the development of, and participation in, a holistic research programme.

In order to set the requirements for and develop logistics knowledge, research organisations and academic institutions - in the private, public and educational sectors - need to adopt a number of roles. The following roles are proposed:

\section{Establish a research agenda}

The need for improvement of the national logistics system implies a need for research to support efforts aimed at improving the system. Logistics is a relatively young and broadly defined field, therefore research organisations need to consolidate their efforts to deliver research products that support national priorities. To this end, a research agenda needs to be defined comprising topics that are both locally relevant and appropriate in the context of developing economies. A central body will be required to coordinate such a research agenda and manage research funding from the Department of Science and Technology, National Research Foundation, NDoT and others.

\section{Explore and enable research capacity and networks}

The wide variety of topics defined under the banner of logistics implies that the capacity for conducting research in all related areas is limited. In addition, the sophistication of roleplayers in logistics in a developing economy varies widely. While sophisticated sectors need to be developing flexible export channels, some players are grappling with the basics of access to cost-effective services. As such, local research in logistics needs to be prioritised, and networks need to be developed with international research institutions to foster research collaboration and early identification of locally relevant research. In addition, networks with research institutions in other developing economies need to be developed, in order to jointly explore questions that are not addressed in mainstream logistics research.

\section{Establish a multidisciplinary approach}

The nature of business in a developing economy implies that the conventional approach of dealing with sophisticated logistics demands is not the only relevant solution. Complexities such as the integration of low-volume supply chains, and the delivery of goods and (government)servicesto remote areas with limited resources, imply thatinnovative approaches need to be developed, and that benefit can be derived from a multidisciplinary approach to logistics research and education. Interfaces need to be created between disciplines such as macro- and developmental economics, sustainability sciences, entrepreneurship, mathematical modelling and industrial engineering. A number of European Union research 
initiatives can be used to fund collaborative research projects that provide opportunities for developing post-graduate researchers. Cooperation with development agencies can also unlock funds for specialised research areas such as humanitarian logistics.

\section{CONCLUSION}

Logistics has a very important role to play in accelerating South Africa's economic development and to increase the country's competitiveness internationally. Logistics infrastructure capacity problems have dominated the logistics debate in recent times, but the NFLS recommendations include a range of interventions. The development and implementation of these interventions require a substantive base of both quantitative and qualitative research.

A number of research themes that warrant prioritisation and further debate have been identified in this paper - these could be adopted by the NFLS task team that is designing and implementing the freight logistics system master plan. At the same time, national research capacity in logistics needs to be strengthened by international research collaboration, with the aim of building local capacity and optimally leveraging international investment in logistics research. A further need exists, namely that of a "central body" which will coordinate the research activities within the country. Where this central body should be vested remains open for debate - one option could be the envisaged national Centre for Logistics Excellence proposed by the NDoT in response to the NFLS (National Department of Transport, 2008).

\section{ACKNOWLEDGEMENTS}

The authors would like to take this opportunity to thank Jim Stock of the University of South Florida, John Bartholdi and John Vande Vate, both from Georgia Tech, Michel Gendrau of the University of Montréal, as well as Peter Kilbourn of the University of Johannesburg and Johan Joubert of the University of Pretoria for their valuable inputs. 


\section{REFERENCES}

Abell, P. and Kay, M. 2005. Breakthrough Connective Technology: How RFID and Other Applications Are Revolutionizing the Supply Chain. Lombard, Illinois: Council for Supply Chain Management Professionals.

Bekker, J., Mostert, M. \& van Dyk, F.E. 2005. Simulation of fruit pallet movement in the port of Durban: A case study. ORiON, 21(1): 63-76.

Bonfatti, F. \& Monari, P.D. 2006. Empowering SMEs to design and operate interlinked logistic networks. In P. Cunningham \& M. Cunningham (Eds), IST-Africa 2006 Conference Proceedings. Dublin: IIMC International Information Management Corporation.

CSIR. 2004. First Annual State of Logistics Survey. Pretoria: CSIR.

CSIR. 2005. Second Annual State of Logistics Survey. Pretoria: CSIR.

CSIR. 2006. Third Annual State of Logistics Survey. Pretoria: CSIR.

Fox, J. 2005. Mediation on Risk: Hurricane Katrina brought out the worst in Washington and the best in business. The lessons of the storm. Fortune, 152(7).

Gélinas, R. \& Bigras, Y. 2004. The characteristics and features of SMEs: Favourable or unfavourable to logistics integration. Journal of Small Business Management, 42(3): 263-278.

Helferich, O.K. and Cook, R.L. 2002. Securing the Supply Chain. Oak Brook, Illinois: Council for Supply Chain Management Professionals.

Hu, M-W. 2003. Many small antelopes make a dragon. Futures 35(4): 379-392.

Hugo, W.M.J., Badenhorst-Weiss, J.A. \& van Biljon, E.H.B. (eds.). 2004. Supply Chain Management - Logistics in Perspective. Pretoria: Van Schaik Publishers.

Kranendonk, R. \& Kersten, P. 2005. Mid-life CoPs: Experiences and Alignment. Proceedings of I-KNOW'05, Graz, Austria: 267-277.

Mpahlwa, M. 2006. Parliamentary media briefing. Cape Town.

National Department of Transport. 2005. National Freight Logistics Strategy. Pretoria. 
National Department of Transport. 2008. Strategic Plan 2008 - 2011. Pretoria.

Ortmann, F.G., van Vuuren, J.H. \& van Dyk, F.E. 2006. Modelling the South African fruit export infrastructure: A case study. ORiON, 22(1): 35-57.

Stock, J.R. \& Broadus, C.J. 2006. Doctoral Research in Supply Chain Management and/or Logistics-related areas: 1999-2004. Journal of Business Logistics, 27(1): 139-358.

Van Dyk, F.E. \& Maspero, E. 2004. An Analysis of the South African fruit logistics infrastructure, ORION, 20(1): 55-72.

Van Wassenhove, L.N. 2006. Humanitarian aid logistics: supply chain management in high gear, J of Op Res Soc, 57(5): 475-489.

Vogt, J.J., Pienaar, W.J. \& de Wit, P.W.C. 2002. Business Logistics Management: Theory and Practice, Cape Town: Oxford University Press Southern Africa.

wwwa. ftp://ftp.cordis.europa.eu/pub/fp6/docs/wp/sp1/f2_wp_200216_en.pdf (Accessed 03/07/08).

wwwb. http://web.mit.edu/scresponse/ (Accessed 03/07/08).

wwwc. http://www.agrologistiek.nl/ (Accessed 03/07/08).

wwwd. http://www.agrologistiek.nl/upl_docs/visie\%20agrologistiek.pdf (Accessed 03/07/08).

wwwe. http://www.apl.com/news/documents/security_white_paper.pdf (Accessed 03/07/08).

wwwf. http://www.businessofgovernment.org/pdfs/GMM.pdf (Accessed 03/07/08).

wwwg. http://www.cargosecurity.com/ncsc/ (Accessed 03/07/08).

wwwh. http://www.cirrelt.ca/?Page=AXESRECHERCHE (Accessed 03/07/08).

wwwi. http://www.civenv.unimelb.edu.au/research/groups/transport.html (Accessed 03/07/08).

wwwj. http://www.connekt.nl/ (Accessed 03/07/08). 
wwwk. http://www.dot.gov.za/frames/sp1008107_1-f.html (Accessed 03/07/08).

wwwl. http://www.fritzinstitute.org/ (Accessed 03/07/08).

wwwm. http://www.insead.edu/v1/humanitarian/ (Accessed 03/07/08).

wwwn. http://www.islamic-relief.co.za/Mozambique\%20flood\%20relief\%202008.htm (Accessed 03/07/08).

wwwo. http://www.laa.asn.au/research_project (Accessed 03/07/08).

wwwp. http://www.Imi.org/logistics/Logistics_05.pdf (Accessed 03/07/08).

wwwq. http://www.maritimesecurityexpo.com/ (Accessed 03/07/08).

wwwr. http://www.nda.agric.za/docs/Cropsestimates/Flood\%20Watch\%20-\%2010-Jan2008final.doc (Accessed 03/07/08).

wwws. www.ndl.nl (Accessed 03/07/08).

wwwt. http://www.sapics.org.za/ (Accessed 03/07/08).

wwwu. http://www.scl.gatech.edu/research/humanitarian/ (Accessed 03/07/08).

wwwv. http://www.stanford.edu/group/scforum/ (Accessed 03/07/08).

wwww. http://www.unjlc.org/about/ (Accessed 03/07/08).

wwwx. http://www.utexas.edu/lbj/pubs/isbn/0-89940-763-3/ (Accessed 03/07/08).

wwwy. http://www.transumo.nl/Nl/Home.aspx (Accessed 03/07/08). 